mission is completed, says Marc Klein Wolt, a Radboud astronomer who is NCLE's manager. But the NCLE might go on collecting data for several years, he says.

\section{SATELLITE BREAK-OFF}

The second experiment that launched with Queqiao consists of two smaller satellites called Longjiang-1 and Longjiang-2, which will detach from the mothership and orbit the Moon. Built by researchers at the Harbin Institute of Technology in China, the instruments will test technology for a radio-astronomy technique called verylong baseline interferometry (VLBI). This approach combines data from multiple radio antennas to create images of much higher resolution than would be possible with a single dish.

Falcke and others have long studied the possibility of doing VLBI with a large array of lunar orbiters - or on the lunar surface - to map variations across the sky in signals from the dark ages and cosmic dawn. Klein Wolt says that his team might experiment with combining data from NCLE with those from the two lunar orbiters, and even from a radio antenna on the Change-4 lander itself.

The Chang'e- 4 mission is another step in China's ambitious lunar-exploration programme, which aims to establish a Moon base in the next decade, and to begin human exploration in the 2030s. The lunar lander will carry a rover and was originally designed as a back-up for Change-3, which in 2013 became the first craft since 1976 to softland (rather than crash-land) on the Moon. Chang'e- 4 has now been repurposed, and the mission's main scientific goal is to study the geology of the hidden side of the Moon, which is pockmarked with many more small craters than the familiar near side.

The lander carries several experiments, including a sealed ecosystem, built by Chongqing University, which will test whether potato and thale-cress (Arabidopsis) seeds sprout and photosynthesize as silkworm eggs hatch and the worms produce carbon dioxide. Another experiment will measure the radiation that will confront future astronauts who visit the lunar surface. The rover, which will separate from the lander to move around the surface of the Moon, will carry instruments such as a solarwind detector built by a Swedish team.

PUBLISHING

Open-access drive
spreads in Europe

Negotiators share tactics to broker new deals with publishers.

\section{BY HOLLY ELSE}

$\mathrm{B}$ old efforts to push academic publishing towards an open-access model are gaining steam. Negotiators from libraries and university consortia across Europe are sharing tactics on how to broker new kinds of contracts that could see more articles appear outside paywalls. And inspired by the results of a stand-off in Germany, they increasingly declare that if they don't like what publishers offer, they will refuse to pay for journal access at all. On 16 May, a Swedish consortium became the latest to say that it wouldn't renew its contract, with publishing giant Elsevier.

Under the new contracts, termed 'read and publish' deals, libraries still pay subscriptions for access to paywalled articles, but their researchers can also publish under open-access terms so that anyone can read their work for free. Advocates say such agreements could accelerate the progress of the open-access movement. Despite decades of campaigning for papers to be published openly - on the grounds that the fruits of publicly funded research should be available for all to read - scholarly publishing's dominant business model remains to publish articles behind paywalls and collect subscriptions from libraries (see 'Growth of open access'). But if many large library consortia strike read-and-publish deals, the proportion of open-access articles could surge.

"There is a serious ground for change across Europe," says Koen Becking, chief negotiator for the VSNU, a consortium of 14 institutes in the Netherlands. In 2014, the VSNU was the first national group to negotiate a subscription deal that included rights for its scholars to publish all of their work openly. It has since agreed several more that include varying levels of open publishing. Consortia in Austria, the United Kingdom, Sweden and Finland have struck similar deals, and Switzerland will start to negotiate its first open-access contracts this year. A survey by the Brussels-based European University Association, published in April, reported that, last year, $11 \%$ of negotiating consortia in Europe made deals that took into account open-access publishing costs, but $63 \%$ planned to do so in the future.

On 2 May, negotiators from countries across Europe agreed to align their bargaining strategies at a closed meeting in Berlin attended by the European Commission's special envoy for open access, Robert-Jan Smits. According to Gerard Meijer, one of the German negotiators present, consortia are "frustrated" by the lack of progress in talks and feel the limits of partnerships between institutions and large publishers "have been reached. It is up to us now to act, and to step out of these negotiations if these are going nowhere," he says.

The meeting was the latest in a string of events in which negotiators from different countries swapped tactics. "More and more people are willing to share their experiences," says Matthijs van Otegem, director of the library at Erasmus University in Rotterdam, and chair of the open-access working group at the Association of European Research Libraries (LIBER) in The Hague, the Netherlands.

In September last year, LIBER published a list of principles to guide negotiators seeking to change their deals. These include ending non-disclosure agreements that publishers customarily place on contracts (which would enable negotiators to compare deals in different countries) and not agreeing to price hikes without open-access agreements in place.

A key driver behind the activity in Europe is the European Commission's goal that, by 2020, all research will be freely accessible as soon as it is published. Dutch negotiators have been tasked with brokering a deal that meets

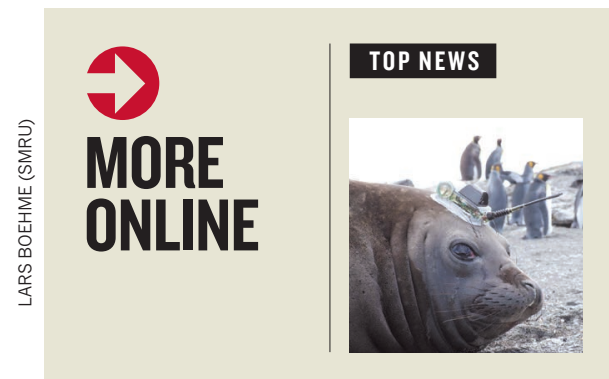

Deep-diving
seals recruited
to measure
climate
change
go.nature.
com/2kdls0h

Deep-diving seals recruite to measure climate go.nature $\mathrm{com} / 2 \mathrm{kdlsO}$

\section{MORE NEWS}

- Share of African American men going into medicine hits historic low go.nature.com/2xlazd3 - Society rescinds award to top seismologist go.nature.com/2lujpfw - UK's powerful funding body takes shape go.nature.com/2x5dsfW

\section{NATURE PODCAST}

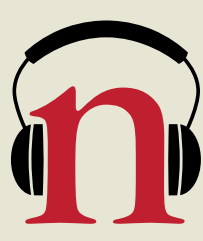

The cost of climate change; cleverer cab journeys; and peering through matter with muons nature.com/nature/ podcast 
this vision. In Sweden, negotiators have set themselves the target of complete openaccess research by 2026, and in Switzerland the planned date is 2024. But word is spreading outside Europe, too: last month, negotiators in Germany travelled to South Korea to discuss their work with consortia there, and representatives from the University of California system attended the Berlin meeting.

\section{DEAL OR NO DEAL}

The situation in Germany has shown that 'no deal' is an option, van Otegem says. Since 2016, a university consortium there has held out on a new deal with Elsevier. Despite the stand-off, the publisher has not stopped German scholars accessing its journals - suggesting that universities need not fear researchers' wrath if negotiations stall. Since then, other consortia have also announced 'no deals' with publishers.

One reason that libraries no longer fear an end to their contracts is that a growing number of free versions of paywalled articles can be found online as preprints or accepted manuscripts, notes Heather Joseph, executive director of the Scholarly Publishing and Academic Resources Coalition (SPARC), an advocacy group in Washington DC. Sci-Hub, a website that illicitly hosts copies of papers and is used by academics around the world, is also a big factor, says Joseph Esposito, a publishing consultant in New York City. "Without Sci-Hub the researchers would be screaming at the libraries and state agencies not to cut them off," he says.

Costs are a major sticking point in the standoffs. A spokesperson for the Royal Society of

\section{GROWTH OF OPEN ACCESS}

In 2016, journals made $18.9 \%$ of papers open immediately on publication, up from $11.5 \%$ in 2012

- Immediate open access (OA)

Immediate hybrid ${ }^{\dagger}$ Open after delay

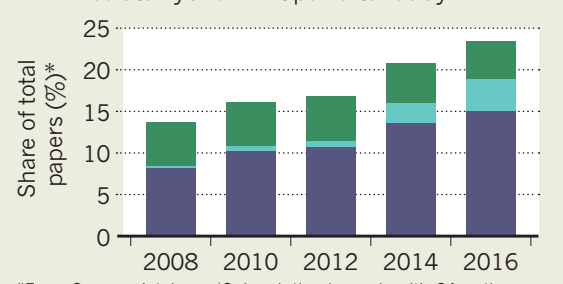

*From Scopus database. Subscription journals with OA option.

Chemistry's publishing arm, for instance, says that its current dispute with the VSNU revolves partly around the difficulty of reaching "an agreement which makes the transition to open access sustainable". (Other publishers approached by Nature's news team declined to comment on details of specific negotiations.)

Consortia are generally unwilling to discuss whether the read-and-publish contracts work out to be more expensive, but some say they don't want to agree to contracts that require above-inflation price rises. And in the United States, where open access has less political impetus than in Europe, libraries are trying to save money by cancelling 'big deal' contracts - comprehensive, but expensive, deals for access to large bundles of journals - in 르워 favour of à la carte access to the journals their academics use the most. This has happened before, but is now a more common approach, according to a list collated by SPARC.

Steven Inchcoombe, Springer Nature's chief publishing officer, says that some deals that combine reading and publishing costs have been brokered in northern Europe because of strong support for open access from research funders, institutions and governments. But unless more money is available to pay for such deals, they are unlikely to become more popular in the future, he says. "It is in everyone's interest to solve this," he adds. (Nature's news team is editorially independent of its publisher.)

If the stand-offs continue, the VSNU's Becking thinks that negotiators might end up striking deals, but might also simply stop bargaining with particular publishers. In that case, universities could encourage researchers to disseminate their work on alternative platforms, he says. 